\title{
Exercise can improve sleep quality: A systematic review and meta-analysis
}

\author{
Masahiro Banno ${ }^{\text {Corresp., }}{ }^{1,2}{ }^{2}$, Yudai Harada ${ }^{2}$, Masashi Taniguchi ${ }^{3,4}{ }^{\text {, Ryo Tobita }}{ }^{3}$, Hiraku Tsujimoto ${ }^{5}$, Yasushi \\ Tsujimoto $^{6,7}$, Yuki Kataoka ${ }^{5,8}$, Akiko Noda ${ }^{9,10}$ \\ 1 Department of Psychiatry, Seichiryo Hospital, Nagoya City, Aichi Prefecture, Japan \\ 2 Department of Psychiatry, Nagoya University Graduate School of Medicine, Nagoya City, Aichi Prefecture, Japan \\ 3 Division of Physical Therapy, Rehabilitation Units, Shiga University of Medical Science Hospital, Otsu City, Shiga Prefecture, Japan \\ 4 Department of Physical Therapy, Graduate School of Medicine, Kyoto University, Kyoto City, Kyoto Prefecture, Japan \\ 5 Hospital Care Research Unit, Hyogo Prefectural Amagasaki General Medical Center, Amagasaki City, Hyogo Prefecture, Japan \\ 6 Department of Healthcare Epidemiology, School of Public Health in the Graduate School of Medicine, Kyoto University, Kyoto City, Kyoto Prefecture, \\ Japan \\ 7 Department of Nephrology and Dialysis, Kyoritsu Hospital, Kawanishi City, Hyogo Prefecture, Japan \\ 8 Department of Respiratory Medicine, Hyogo Prefectural Amagasaki General Medical Center, Amagasaki City, Hyogo Prefecture, Japan \\ 9 Chubu University Graduate School of Life and Health Sciences, Kasugai City, Aichi Prefecture, Japan \\ 10 Clinical Laboratory Technical Education Center, Chubu University, Kasugai City, Aichi Prefecture, Japan \\ Corresponding Author: Masahiro Banno \\ Email address: solvency@med.nagoya-u.ac.jp
}

Background. Insomnia is common. However, no systematic reviews have examined the effect of exercise on patients with primary and secondary insomnia, defined as both sleep disruption and daytime impairment. This systematic review and meta-analysis aimed to examine the effectiveness/efficacy of exercise in patients with insomnia. Methods. We searched the Cochrane Central Register of Controlled Trials, MEDLINE, Embase, PsycINFO, World Health Organization International Clinical Trials Registry Platform, and ClinicalTrials.gov to identify all randomized controlled trials that examined the effects of exercise on various sleep parameters in patients with insomnia. All participants were diagnosed with insomnia, using standard diagnostic criteria or predetermined criteria and standard measures. Data on outcome measures were subjected to meta-analyses using random-effects models. The Cochrane Risk of Bias Tool and Grading of Recommendations, Assessment, Development, and Evaluation approach were used to assess the quality of the individual studies and the body of evidence, respectively. Results. We included nine studies with a total of 557 participants. According to the Pittsburgh Sleep Quality Index (mean difference [MD], 2.87 points lower in the intervention group; 95\% confidence interval [Cl], 3.95 points lower to 1.79 points lower; low-quality evidence) and Insomnia Severity Index (MD, 3.22 points lower in the intervention group; $95 \% \mathrm{Cl}, 5.36$ points lower to 1.07 points lower; very low-quality evidence), exercise was beneficial. However, exercise interventions were not associated with improved sleep efficiency (MD, 0.56\% 
lower in the intervention group; $95 \% \mathrm{Cl}, 3.42 \%$ lower to $2.31 \%$ higher; moderate-quality evidence). Only four studies noted adverse effects. Most studies had a high or unclear risk of selection bias. Discussion. Our findings suggest that exercise can improve sleep quality without notable adverse effects. Most trials had a high risk of selection bias. Higher quality research is needed. Registration number. CRD42016046064 in the National Institute for Health Research PROSPERO register 
1 Exercise can improve sleep quality: A systematic review and meta-analysis

2 Masahiro Banno $^{1,2}$, Yudai Harada ${ }^{2}$, Masashi Taniguchi ${ }^{3,4}$, Ryo Tobita ${ }^{3}$, Hiraku Tsujimoto ${ }^{5}$,

3 Yasushi Tsujimoto ${ }^{6,7}$, Yuki Kataoka ${ }^{5,8}$, Akiko Noda ${ }^{9,10}$

$5{ }^{1}$ Department of Psychiatry, Seichiryo Hospital, Nagoya City, Aichi Prefecture, Japan

$6 \quad{ }^{2}$ Department of Psychiatry, Nagoya University Graduate School of Medicine, Nagoya City,

7 Aichi Prefecture, Japan

$8 \quad{ }^{3}$ Division of Physical Therapy, Rehabilitation Units, Shiga University of Medical Science

9 Hospital, Otsu City, Shiga Prefecture, Japan

$10{ }^{4}$ Department of Physical Therapy, Graduate School of Medicine, Kyoto University, Kyoto City,

11 Kyoto Prefecture, Japan

$12{ }^{5}$ Hospital Care Research Unit, Hyogo Prefectural Amagasaki General Medical Center,

13 Amagasaki City, Hyogo Prefecture, Japan

$14{ }^{6}$ Department of Healthcare Epidemiology, School of Public Health in the Graduate School of

15 Medicine, Kyoto University, Kyoto City, Kyoto Prefecture, Japan

$16{ }^{7}$ Department of Nephrology and Dialysis, Kyoritsu Hospital, Kawanishi City, Hyogo Prefecture,

17 Japan

$18{ }^{8}$ Department of Respiratory Medicine, Hyogo Prefectural Amagasaki General Medical Center,

19 Amagasaki City, Hyogo Prefecture, Japan

$20{ }^{9}$ Chubu University Graduate School of Life and Health Sciences, Kasugai City, Aichi

21 Prefecture, Japan

$22{ }^{10}$ Clinical Laboratory Technical Education Center, Chubu University, Kasugai City, Aichi

23 Prefecture, Japan 
25 Corresponding author:

26 Masahiro Banno ${ }^{1,2}$

27

28 Email address: solvency@med.nagoya-u.ac.jp

29

30

31

32 Author name abbreviations: Masahiro Banno (MB), Yudai Harada (YH), Masashi Taniguchi

33 (MT), Ryo Tobita (RT), Hiraku Tsujimoto (HT), Yasushi Tsujimoto (YT), Yuki Kataoka (YK),

34 Akiko Noda (AN)

35 


\section{ABSTRACT}

38 Background. Insomnia is common. However, no systematic reviews have examined the effect

39 of exercise on patients with primary and secondary insomnia, defined as both sleep disruption

40 and daytime impairment. This systematic review and meta-analysis aimed to examine the

41 effectiveness/efficacy of exercise in patients with insomnia.

42 Methods. We searched the Cochrane Central Register of Controlled Trials, MEDLINE, Embase,

43 PsycINFO, World Health Organization International Clinical Trials Registry Platform, and

44 ClinicalTrials.gov to identify all randomized controlled trials that examined the effects of

45 exercise on various sleep parameters in patients with insomnia. All participants were diagnosed

46 with insomnia, using standard diagnostic criteria or predetermined criteria and standard

47 measures. Data on outcome measures were subjected to meta-analyses using random-effects

48 models. The Cochrane Risk of Bias Tool and Grading of Recommendations, Assessment,

49 Development, and Evaluation approach were used to assess the quality of the individual studies

50 and the body of evidence, respectively.

51 Results. We included nine studies with a total of 557 participants. According to the Pittsburgh

52 Sleep Quality Index (mean difference [MD], 2.87 points lower in the intervention group; 95\%

53 confidence interval [CI], 3.95 points lower to 1.79 points lower; low-quality evidence) and

54 Insomnia Severity Index (MD, 3.22 points lower in the intervention group; 95\% CI, 5.36 points

55 lower to 1.07 points lower; very low-quality evidence), exercise was beneficial. However,

56 exercise interventions were not associated with improved sleep efficiency (MD, 0.56\% lower in

57 the intervention group; $95 \%$ CI, 3.42\% lower to $2.31 \%$ higher; moderate-quality evidence). Only

58 four studies noted adverse effects. Most studies had a high or unclear risk of selection bias. 
59 Discussion. Our findings suggest that exercise can improve sleep quality without notable adverse

60 effects. Most trials had a high risk of selection bias. Higher quality research is needed.

61 Registration number. CRD42016046064 in the National Institute for Health Research

62 PROSPERO register 


\section{INTRODUCTION}

65

66

67

68

69

70

71

72

73

74

75

76 77 (Passos et al., 2012).

Approximately $30 \%$ of the general population experience sleep disruption, while $10 \%$ experience both sleep disruption and daytime dysfunction consistent with a diagnosis of insomnia as defined by the National Institutes of Health (National Institutes of Health, 2005). Patients with insomnia are at high risk of developing hypertension, atherosclerosis, and acute myocardial infarction (Laugsand et al., 2011; Fernandez-Mendoza et al., 2012; Nakazaki et al., 2012). Insomnia is strongly correlated with mental illness and poses an additional risk for depression as well as suicidal ideation and behavior (Baglioni et al., 2011; Bjorngaard et al., 2011; Pigeon, Pinquart \& Conner, 2012). Pharmacotherapy is an effective treatment for patients with insomnia. However, the use of hypnotics is associated with increased mortality (Kripke, 2016), and the frequency of falls and hip fractures increases when hypnotics are used in elderly individuals (Allain et al., 2005). Cognitive behavioral therapy for insomnia (CBT-I), the first-line treatment for insomnia (Morin et al., 2006), requires frequent monitoring and has a high cost

Exercise is a nonpharmacological therapy for insomnia, is readily available, and costs less than other nonpharmacological treatments for insomnia; notably, its effects depend upon exercise type and evaluation methodology (Youngstedt, O'Connor \& Dishman, 1997; Driver \& Taylor, 2000; Youngstedt, 2005). Recent randomized controlled trials (RCTs) have confirmed that exercise has positive effects on sleep quality, sleep onset latency, total sleep time, sleep efficiency, and insomnia severity (Passos et al., 2010; Reid et al., 2010; Hartescu, Morgan \& Stevinson, 2015). Epidemiological studies have clarified the association between exercise and decreased complaints of insomnia (De Mello, Fernandez \& Tufik, 2000; Youngstedt \& Kline, 2006), as well as a relationship between lower levels of physical activity and a greater prevalence 
87 of insomnia (Morgan, 2003). Among the main symptoms of insomnia, such as difficulty

88 initiating sleep (DIS) or early morning awakening (EMA) (Lichstein et al., 2003), EMA is more

89 frequently observed in older adults than other symptoms (Kim et al., 2000). These symptoms are

90 associated with circadian core body temperature. Patients with DIS have a delayed core body

91 temperature rhythm, whereas those with EMA have an advanced rhythm (Lack et al., 2008).

92 However, experimental investigations of the effects of exercise on sleep in individuals with

93 insomnia are lacking.

94 The fifth edition of the Diagnostic and Statistical Manual of Mental Disorders (DSM-5)

95 and the third edition of the International Classification of Sleep Disorders (ICSD-3) made major

96 revisions to their definitions of insomnia. The DSM-5 and ICSD-3 abolished the distinction

97 between primary and secondary insomnia. The revision was based on the findings that insomnia:

98 1) often accompanies another disease, 2) is preceded by a comorbid condition, 3) persists even

99 after effective treatment for the comorbid condition, and 4) exacerbates the symptoms of the

100 comorbid condition (Riemann et al., 2015). Previous systematic reviews and/or meta-analyses

101 investigated the effects of exercise in people with sleep complaints or chronic insomnia (Passos

102 et al., 2012), undefined populations (Kubitz et al., 1996; Youngstedt, O'Connor \& Dishman,

103 1997; Kredlow et al., 2015), and patients with sleep problems (Montgomery \& Dennis, 2002;

104 Montgomery \& Dennis, 2004; Yang et al., 2012). A previous review also examined the effects of 105 exercise on sleep in specific subpopulations (e.g., cancer survivors) (Mercier, Savard \& Bernard, 106 2017). However, no previous systematic reviews have examined the effect of exercise in patients 107 with primary and secondary insomnia as defined by having both sleep disruption and daytime 108 impairment. Investigating the effect of exercise in patients with primary and secondary insomnia 
109 would be beneficial in clinical practice since DSM-5 and ICSD-3 abolished the distinction

110 between the two.

111

112 STUDY OBJECTIVES

113 This review aimed to examine the effects of exercise in patients with insomnia.

115 MATERIALS AND METHODS

116 This systematic review was conducted according to the PRISMA statement (Liberati et

117 al., 2009). Table S1 shows the PRISMA 2009 checklist. The detailed methods are described in

118 CRD42016046064 in the National Institute for Health Research PROSPERO register.

\section{ELIGIBILITY CRITERIA}

\section{Study type}

We included all published and unpublished RCTs, including those that were only

123 abstracts or letters. Crossover trials and cluster-, quasi-, and non-randomized trials were

124 excluded. Studies in any language from any country were accepted for screening. Studies were

125 included regardless of the follow-up period.

127 Participants

128 Participants included those diagnosed with insomnia using any standard diagnostic

129 criteria such as DSM, International Classification of Diseases, ICSD, Research Diagnostic

130 Criteria (RDC) for insomnia, or predetermined criteria and standard measures (i.e., Pittsburgh

131 Sleep Quality Index [PSQI] (Buysse et al., 1989), Insomnia Severity Index [ISI] (Bastien, 
132 Vallieres \& Morin, 2001), and a sleep questionnaire). The American Academy of Sleep

133 Medicine developed standard definitions for insomnia disorders, such as the RDC for insomnia

134 (Edinger et al., 2004). We utilized the PSQI and ISI in our inclusion criteria because both are

135 appropriate screening tools for insomnia (Chiu et al., 2016). All participants had insomnia-

136 related daytime impairments or were screened using sleep questionnaires including items about

137 such impairments. Recent RCTs were beyond the scope of this review because participants in

138 these studies did not have insomnia-related daytime impairments (Gebhart, Erlacher \& Schredl,

139 2011; Chen et al., 2016; Tan et al., 2016).

140 The cutoff value for the PSQI global score used to diagnose a sleep disorder was defined

141 by the trial list. If a study did not specify a cutoff value, we surmised that a PSQI global score >

1425 would be considered insomnia (Backhaus et al., 2002). We included patients of any age, sex,

143 race, and setting, but excluded those with sleep apnea syndrome. We also checked the inclusion

144 criteria for insomnia and the sleep questionnaire to determine whether the screening process

145 selected those with daytime impairment.

147 Interventions

148 The interventions were predetermined exercise programs. Interventions of any intensity,

149 duration, and frequency were included. We included exercise in combination with medication if

150 participants in the intervention and control groups were taking the same medication. We

151 excluded interventions recommending that patients increase physical activity or encouraging

152 improvement in self-efficacy through CBT, a mind-body bridging program, a mindfulness

153 meditation program, massage therapy, or breathing techniques without physical activity. We

154 examined the following interventions and comparisons: 
155 1) Exercise versus non-exercise and non-medication control; and

156 2) Exercise plus medication versus medication alone.

157 We excluded the following intervention: Exercise combined with another treatment (e.g., 158 CBT).

159

160 OUTCOME MEASURES

161 The following primary outcomes were measured:

162 1. Sleep quality according to the PSQI;

163 2. Sleep efficiency defined by the percentage of time spent in bed asleep as measured objectively

164 by a sleep device (e.g., polysomnography [PSG], actigraphy) or by reports/diaries kept by a

165 partner or nursing staff; and

166 3. Insomnia severity according to a standard measure (ISI).

167

168 Secondary outcomes were as follows:

169 1. Quality of life (QOL) as measured by standardized questionnaires with established reliability

170 and validity, such as the Short Form 36 (SF-36);

171 2. Sleep onset latency as measured objectively by sleep devices (e.g., PSG, actigraphy) or

172 reports/diaries maintained by a partner or nursing staff;

173 3. Total sleep time as measured objectively by a sleep device (e.g., PSG, actigraphy) or

174 reports/diaries maintained by a partner or nursing staff;

175 4. All adverse events (defined by the trial list);

176 5. Sleepiness during daily life according to a self-report using a standardized measure, e.g., the

177 Epworth Sleepiness Scale (ESS); 
178 6. Current sleepiness according to a self-report using a standardized measure, e.g., the Stanford

179 Sleepiness Scale (SSS);

180 7. Wake after sleep onset (WASO) as measured objectively by a sleep device (e.g., PSG,

181 actigraphy) or reports/diaries maintained by a partner or nursing staff;

1828 . Anxiety according to a standardized questionnaire with established reliability and validity

183 (e.g., State-Trait Anxiety Inventory); and

184 9. Depression according to a standardized questionnaire with established reliability and validity

185 (e.g., Beck Depression Inventory).

186 We consulted an expert in sleep medicine (AN) and experts in exercise therapy (MT and

187 RT) and selected the moderator (primary and secondary outcomes, prioritization of outcomes,

188 and subgroup analysis items) in terms of clinical importance.

189

190 SEARCH METHODS FOR STUDY IDENTIFICATION

191 Electronic searches

192 To identify relevant trials, we searched the following electronic databases on October 9,

1932016 and updated the electronic searches on October 4, 2017:

194 1. The Cochrane Central Register of Controlled Trials (CENTRAL);

195 2. MEDLINE via EBSCOhost;

196 3. Embase; and

197 4. PsycINFO via PsycNET.

198 See Appendix S1 for details about the search strategies.

199

200 Searches of other resources 
We also searched the following registries to identify completed but unpublished trials and

202 investigate reporting bias.

203 1. World Health Organization International Clinical Trials Registry Platform; and

204 2. ClinicalTrials.gov.

205 See Appendix S1 for details of the search strategies.

206 We also manually searched reference lists in clinical guidelines on exercise for insomnia

207 and in related guidelines (Morgenthaler et al., 2006; Bauer et al., 2007; Wilson et al., 2010;

208 NICE, 2012; Bauer et al., 2013; NICE, 2013; University of Texas at Austin School of Nursing.,

209 2014; Bauer et al., 2015; NICE, 2015; Qaseem et al., 2016), reference lists of extracted studies,

210 and articles citing the extracted studies.

211 We contacted authors if the extracted studies lacked the necessary information.

212

213 DATA COLLECTION AND ANALYSIS

214 Study selection

215 Two of the five authors (MB, YH, HT, YT, and YK) independently screened the titles

216 and abstracts of the articles identified in the search. Two of the five authors were assigned to

217 each article to reduce the burden on each author. They assessed eligibility based on a full-text

218 review. Disagreement was resolved by discussion; if necessary, YK or YT (if YK and an author

219 other than YT were the two authors) or MB (if YK and YT were the two authors) provided

220 arbitration. We followed a pre-defined protocol to screen the abstracts and full texts and used

221 pre-defined criteria in the registered protocol. One lead author (MB) checked all included studies

222 and the exclusion criteria for all records subjected to the full-text screening procedure. Therefore,

223 the decision would not differ systematically. 
225 Data extraction and management

226 The data were extracted on prespecified forms that were piloted using a random sample

227 of 10 studies. Two of the four authors (MB, HT, YT, and YK) independently extracted the data.

$228 \mathrm{MB}$ and another author were assigned to each article to reduce the burden on each author. We

229 contacted the authors of studies lacking sufficient information as necessary. Differences in data

230 extraction opinions were resolved by discussion and arbitrated by YK or YT (if YK was the

231 other author) when necessary. See Appendix S2 for details of the extracted information.

232

233 Assessment of risk of bias of the included studies

234 Two of the four authors (MB, HT, YT, and YK) independently assessed the risk of bias

235 of the included studies using the Cochrane Risk of Bias Tool (Higgins \& Green, 2011). MB and

236 another author were assigned to each article to reduce the burden on each author. Differences in

237 opinion about the assessment of risk of bias were resolved by discussion and through arbitration

238 by YK or YT (if YK was the other author) as necessary.

Measures of treatment effect

For continuous outcomes (sleep quality, sleep efficiency, insomnia severity, QOL, sleep

242 onset latency, total sleep time, sleepiness during daily life, current sleepiness, WASO, anxiety, 243 and depression), the standardized mean difference (SMD) or mean difference (MD) with 95\% CI

244 was calculated as recommended by the Cochrane handbook (Higgins \& Green, 2011). We used

245 MD when data including meta-analyses were derived from the same indicator. We used SMD

246 when data including meta-analyses were derived from different indicators or we compared the 
247 data in the meta-analysis with data in a previous study using SMD. Adverse events were narratively summarized since the definition of these outcomes varied among studies.

Assessment of heterogeneity

We first assessed heterogeneity by visual inspection of the forest plots. We also

252 253

\section{Data synthesis}

We pooled the data using a random-effects model. The DerSimonian and Laird method was used in the random-effects meta-analysis (DerSimonian \& Laird, 1986). All analyses were conducted using Review Manager software (RevMan 5.3, The Nordic Cochrane Centre, The Cochrane Collaboration, Copenhagen, Denmark).

\section{Subgroup analysis and investigation of heterogeneity}

We further aimed to identify possible causes of heterogeneity. The following prespecified subgroup analyses of the primary outcomes were planned: 1) sex;2) primary and secondary insomnia; 3 ) exercise duration: short-term ( $<2$ months), medium-term ( 2 to $<6$ months), longterm (>= 6 months); 4) exercise intensity: aerobic versus anaerobic exercise; 5) exercise type: 
269 aerobic (walking), resistance, and aerobic plus resistance; and 6) exercise setting or location:

270 home, physical therapy center, hospital, or elsewhere.

271

272 Sensitivity analysis

273 The following prespecified sensitivity analyses of the primary outcomes were planned: 1)

274 repeating the analysis but restricting it to studies with low risks of bias from random sequence

275 generation and allocation concealment, using the Cochrane Risk of Bias Tool (Higgins \& Green,

276 2011); 2) repeating the analysis using a fixed-effects model instead of random-effects model; and

277 3) excluding studies with "a per-protocol analysis" or "analysis including imputed data."

278

279 Summary of findings tables

280 The main results of our review are presented in the Summary of findings table (Table 1),

281 which includes an overall grading of the evidence related to each of the main outcomes using the

282 Grading of Recommendations, Assessment, Development, and Evaluation (GRADE) approach

283 (Guyatt et al., 2011; Higgins \& Green, 2011).

284

285 Registration

286 We registered the protocol in the National Institute for Health Research PROSPERO

287 register (www.crd.york.ac.uk/PROSPERO/display_record.asp?ID=CRD42016046064).

289 RESULTS

290 SEARCH RESULTS 
After removing duplicates, we identified 4,085 records during the search conducted in

292 October 2016 and updated the electronic searches on October 4, 2017 (Fig. 1). We included 17

293 trials in the qualitative synthesis and detected seven unpublished trials and one completed trial

294 without outcomes data (Chan et al., 2017). Ultimately, 557 participants in nine trials were

295 included in the quantitative synthesis.

296 Table 2 summarizes the published studies included in the qualitative synthesis. Table S2

297 shows the characteristics of the seven unpublished trials. Table S3 shows the sleep medications

298 used in the included completed trials.

299 The bias risk of the quantitative synthesis is shown in Fig. 2A and 2B.

300

301 PRIMARY OUTCOMES

302 1. Sleep quality

303 Data from six trials comprising 361 participants that measured sleep quality were pooled in our

304 meta-analysis (Reid et al., 2010; Tang, Liou \& Lin, 2010; Irwin et al., 2014; Hartescu, Morgan \&

305 Stevinson, 2015; Chan et al., 2016; Tadayon, Abedi \& Farshadbakht, 2016) (Fig. 3A). All trials

306 measured PSQI and had an intervention period of 8 weeks to 6 months. There was a significant

307 effect noted in favor of the intervention (MD, 2.87 points lower in the intervention group; 95\%

308 CI, 3.95 points lower to 1.79 points lower; $\mathrm{P}<0.001$; low-quality evidence). A lower score was

309 more beneficial in PSQI. Substantial heterogeneity was observed $\left(\mathrm{Tau}^{2}=1.18 ; \mathrm{I}^{2}=68 \%\right)$.

310 2. Sleep efficiency

311 Data from four trials that examined sleep efficiency in 186 participants were pooled in our meta-

312 analysis (Passos et al., 2010; Afonso et al., 2012; Irwin et al., 2014; Hartescu, Morgan \&

313 Stevinson, 2015) (Fig. 3B). All trials measured sleep efficiency with PSG and actigraphy and 
314 had an intervention period of 1 day to 6 months. There was no significant improvement in favor

315 of the intervention (MD, $0.56 \%$ lower in the intervention group; $95 \% \mathrm{CI}, 3.42 \%$ lower to $2.31 \%$

316 higher; $\mathrm{P}=0.70$; moderate-quality evidence). A higher percentage was more beneficial for sleep

317 efficiency. No statistical heterogeneity was indicated $\left(\mathrm{Tau}^{2}<0.001 ; \mathrm{I}^{2}=0 \%\right)$.

318

319 3. Insomnia severity

320 Data from two trials that measured insomnia severity in 66 participants were pooled in our meta-

321 analysis (Afonso et al., 2012; Hartescu, Morgan \& Stevinson, 2015) (Fig. 3C). All trials

322 measured ISI and had an intervention period of 4-6 months. There was significant improvement

323 in favor of the intervention (MD, 3.22 points lower in the intervention group; 95\% CI, 5.36

324 points lower to 1.07 points lower; $\mathrm{P}=0.003$; very low-quality evidence). A lower score was

325 more beneficial in ISI. No statistical heterogeneity was indicated $\left(\mathrm{Tau}^{2}<0.001 ; \mathrm{I}^{2}=0 \%\right)$.

326

327 SECONDARY OUTCOMES

328 1. QOL

329 Five trials examined QOL, but the data were not subjected to the meta-analysis or assessed by

330 the GRADE approach because concepts of QOL measures differed among the trials. The 12-item

331 medical outcomes study short form health survey version 2.0 (SF-12v2) or SF-36 had two types

332 of scores (physical component summary and mental component summary). Other QOL

333 instruments had a single total score. Therefore, we did not calculate the SMD of the QOL

334 instruments. Significant effects in favor of the intervention were noted in all trials (Fig. S1-S14;

335 Table S4).

336 2. Sleep onset latency 
337 Data from five trials that measured sleep onset latency (min) in 206 participants were pooled for

338 the meta-analysis (Guilleminault et al., 1995; Passos et al., 2010; Afonso et al., 2012; Irwin et al.,

339 2014; Hartescu, Morgan \& Stevinson, 2015). All trials measured sleep onset latency using PSG

340 and actigraphy and had an intervention period of 1 day to 6 months. There was no significant

341 improvement in favor of the intervention (MD, 1.90 min higher in the intervention group; $95 \%$

$342 \mathrm{CI}, 3.63 \mathrm{~min}$ lower to $7.43 \mathrm{~min}$ higher; $\mathrm{P}=0.50$; low-quality evidence). Shorter duration was

343 more beneficial for sleep onset latency. No statistical heterogeneity was indicated $\left(\mathrm{Tau}^{2}<0.001\right.$;

$\left.344 \quad I^{2}=0 \%\right)($ Fig. S15; Table S4).

345 3. Total sleep time

346 Data from five trials that examined total sleep time (min) in 206 participants were pooled for the

347 meta-analysis (Guilleminault et al., 1995; Passos et al., 2010; Afonso et al., 2012; Irwin et al.,

348 2014; Hartescu, Morgan \& Stevinson, 2015). All trials measured total sleep time using PSG and

349 actigraphy and had an intervention period of 1 day to 6 months. There was no significant

350 improvement in favor of the intervention (MD, 4.32 min higher in the intervention group; $95 \%$

$351 \mathrm{CI}, 9.19 \mathrm{~min}$ lower to 17.84 min higher; $\mathrm{P}=0.53$; low-quality evidence). Longer duration was

352 more beneficial for total sleep time. No statistical heterogeneity was indicated $\left(\mathrm{Tau}^{2}<0.001 ; \mathrm{I}^{2}=\right.$ 353 0\%; Fig. S16; Table S4).

354 4. All adverse events (defined by the trial list)

355 Four trials comprising 150 participants measured adverse events. Three trials found no adverse

356 events in any of the participants (Reid et al., 2010; Afonso et al., 2012; Chan et al., 2016). One

357 trial described one adverse event, a mild sprained ankle, in the intervention group (Hartescu,

358 Morgan \& Stevinson, 2015). Follow-up was 2-6 months (very low-quality evidence).

359 5. Other secondary outcomes (Secondary outcomes not including Summary of findings table) 
360 Anxiety and depression were significantly ameliorated in favor of the intervention (Figs. S17 and

361 S18; Table S4). ESS and WASO did not detect a significant effect in favor of the intervention

362 (Figs. S19 and S20; Table S4). None of the trials measured SSS (Fig. S21; Table S4).

363

364 ADDITIONAL ANALYSES

365 We performed subgroup analyses of sleep quality because the outcome showed an $\mathrm{I}^{2}>$

$36650 \%$. We conducted an ad-hoc subgroup analysis for exercise frequency (acute or regular)

367 because the underlying mechanisms may differ between acute exercise and regular exercise. We

368 also conducted an ad-hoc subgroup analysis of background variables (cancer patients,

369 postmenopausal women, and others). The exercise type subgroups differed significantly (P<

370 0.001; Table S4) and other pre-specified and ad-hoc subgroups of sleep quality did not differ

371 significantly (Table S4). Sleep efficiency did not improve significantly in favor of the

372 intervention with acute exercise (MD, 0.50\% lower in the intervention group; 95\% CI, 8.31\%

373 lower to $7.31 \%$ higher; $\mathrm{P}=0.90)$ or regular exercise $(\mathrm{MD}, 0.56 \%$ lower in the intervention

374 group; $95 \% \mathrm{CI}, 3.64 \%$ lower to $2.52 \%$ higher; $\mathrm{P}=0.72$; Table S4). A higher percentage was

375 more beneficial for sleep efficiency.

376 We conducted sensitivity analysis by restricting the analyzed studies to those that had a

377 low risk of selection bias; however, the results were the same as those obtained in the original

378 analysis (Table S4). Moreover, the results did not change with the use of a fixed-effects model

379 instead of a random-effects model (Table S4). We were unable to estimate the ISI results, as

380 none of the trials showed a low risk of selection bias (Table S4).

381 When studies using imputed data or per-protocol analysis were excluded, PSQI (two

382 trials with 164 participants) did not exhibit a significant effect in favor of the intervention (MD, 
3832.21 points lower in the intervention group; $95 \%$ CI, 5.34 points lower to 0.92 point higher). A

384 lower score was more beneficial for PSQI. Sleep efficiency (one trial with 48 participants) did

385 not significantly improve in favor of the intervention (MD, $0.50 \%$ lower in the intervention

386 group; 95\% CI, 8.31\% lower to 7.31\% higher). A higher percentage was more beneficial for

387 sleep efficiency. We were unable to estimate the ISI results because no trials remained after

388 exclusion of those with imputed data or per-protocol analysis (Table S4).

389 We conducted an ad-hoc sensitivity analysis by excluding one study with acute exercise

390 because it was an experimental RCT. When the study with acute exercise was excluded, sleep

391 efficiency did not significantly improve in favor of the intervention (MD, $0.56 \%$ lower in the

392 intervention group; 95\% CI, 3.64\% lower to 2.52\% higher). A higher percentage was more

393 beneficial for sleep efficiency.

394

395 DISCUSSION

396 The pooled results revealed that exercise improves PSQI and ISI scores. These results

397 were consistent across the included trials despite the indication of substantial heterogeneity in the

398 PSQI. The heterogeneity of PSQI seemed to be explained by exercise type. Whether exercise

399 improves QOL was inconclusive in our study, although exercise did have some adverse effects

400 which were of little importance. These results suggested that exercise was an effective

401 nonpharmacological treatment because improved sleep quality is one of the primary treatment

402 goals (Schutte-Rodin et al., 2008). Furthermore, a recent comprehensive narrative review

403 strongly recommended aerobic exercise in subjects with sleep disorders (Chennaoui et al., 2015).

404 Exercise can be as promising a nonpharmacological intervention for patients with insomnia as 405 CBT-I. 


\section{RESULTS COMPARED TO THOSE OF PRIOR STUDIES}

408

410

411

412

413

414

416

A three-point change in PSQI score was chosen to indicate a minimal clinically important difference (MCID) (Hughes et al., 2009). Therefore, the effect of exercise on PSQI in favor of the intervention (low-quality evidence) was considered small. A previous study (Yang et al., 2012) found a small-to-moderate effect (SMD, 0.47; 95\% CI, 0.08-0.86) of exercise on PSQI among patients with sleep complaints, whereas our study found that exercise exerts a large effect (SMD, 1.00; 95\% CI, 0.48-1.53) on the PSQI. These results suggest that exercise may provide more beneficial effects on PSQI in patients with insomnia than in participants with sleep complaints. There is a possible ceiling and floor effect of exercise on sleep in patients with sleep complaints compared to those with insomnia (Chennaoui et al., 2015). For example, baseline total PSQI scores may be higher in patients with insomnia than in those with sleep complaints, which may explain the differences in the results of these studies.

Since a change in ISI score greater than 7 would be considered moderate improvement (Morin et al., 2011), the effect of exercise on ISI (MD, 3.22 points lower in the intervention group; 95\% CI, 5.36 points lower to 1.07 points lower; very low-quality of evidence) in favor of the intervention was considered small. The only previous study using PSG (Yang et al., 2012) detected no change in sleep efficiency or onset latency, which was consistent with results on these two parameters in our study.

In the present study, exercise did not improve sleep efficiency, sleep onset latency, or total sleep time, and there was no evidence of heterogeneity across studies. The non-randomized crossover study demonstrated an acute morning exercise decrease in the arousal index and the number of stage shifts during the second half of the night in older individuals with insomnia 
429 (Morita, Sasai-Sakuma \& Inoue, 2017). A polysomnographic and subjective sleep study found a

430 significant decrease in sleep onset latency and wake time after sleep onset as well as a significant

431 increase in sleep efficiency following a 6-month exercise training program, but no significant

432 differences were seen between morning and late-afternoon exercise in chronic primary insomnia

433 (Passos et al., 2011). Inconsistent subjective and objective results regarding the effects of

434 exercise on sleep, which may be related to variations in exercise intensity, and time between

435 exercise and sleep, were reported. Moreover, acute exercise affects the endocrine system

436 (Tuckow et al., 2006), metabolism (Scheen et al., 1996), and core body temperature (Murphy \&

437 Campbell, 1997; Gilbert et al., 2004). Regular exercise affects the endocrine system (Kern et al., 438 1995), metabolism (Scheen et al., 1996), circadian rhythm and body core temperature (Murphy

439 \& Campbell, 1997). Sleep loss may affect metabolism, the central nervous system, the endocrine 440 system, inflammation, and the autonomic nervous system (Chennaoui et al., 2015). Some studies

441 have focused on the sleep process in insomnia. Regular daytime exercise can increase melatonin

442 secretion in and improve the sleep quality of patients with insomnia (Taheri \& Irandoust, 2018).

443 Insomnia can also result in cognitive dysfunction because sleep may restore cognitive function

444 and maintain attentional mechanisms (Taheri \& Arabameri, 2012). Thus, the beneficial effects of

445 exercise on sleep efficiency and onset latency contribute to the interaction between circadian

446 rhythm and metabolic, immune, thermoregulatory, and endocrine effects. Future trials to

447 investigate the effects of exercise on sleep cycle and sleep process in patients with insomnia are 448 required.

450 SUMMARY OF THE FINDINGS AND RECOMMENDATONS 
452 sleep in patients with insomnia (diagnosed using criteria or screened with questionnaires). Our

453 findings suggest that the effects of exercise on sleep were greater in patients with insomnia than

454 in other populations and should be an effective nonpharmacological intervention. Exercise

455 interventions may alleviate symptoms in patients with insomnia without use of hypnotics. The

456 American Academy of Sleep Medicine report does not include exercise as a viable

457 recommendation for treating insomnia (Morgenthaler et al., 2006). Our findings suggest that

458 future clinical practice guidelines should include exercise as a recommendation for treating

459 patients with insomnia.

460

461 STRENGTHS

462 The primary strength of this study was its careful and rigorous screening, extraction, and scoring

463 process. The secondary strength was the extensive subgroup analyses that explored the

464 heterogeneity of the results.

465

466 LIMITATIONS

467 Our study has several limitations. First, only four of the nine included trials examined

468 adverse effects (Reid et al., 2010; Afonso et al., 2012; Hartescu, Morgan \& Stevinson, 2015).

469 Therefore, unreported outcomes and important unmeasured outcomes such as adverse effects (for

470 example, arrhythmia) may exist (Andersen et al., 2013). Second, most studies had a high or

471 unclear risk of selection bias, although our sensitivity analysis revealed that the results were

472 unchanged when studies were restricted to those that had a low risk of selection bias (Table S4).

473 In the future, trials with low risks of selection bias need to be conducted verify our findings. 
474 Third, our review did not consider menopause in the meta-analysis because none of the included

475 studies reported subgroup data by postmenopausal status. In the future, trials with subgroup data 476 on postmenopausal women compared with women of other age groups are needed to determine 477 the effects of exercise in patients with insomnia.

478

479 CONCLUSIONS

480 Our findings suggest that exercise can improve sleep quality without notable adverse 481 effects in patients with insomnia. Most of the trials included in our review suggested a high risk 482 of selection bias in some domains. Therefore, higher quality research is needed to clarify the 483 effects of exercise on sleep in patients with insomnia.

485 ACKNOWLEDGEMENTS

486 We are grateful to Mr. Rui Afonso (Departamento de Psicobiologia, Universidade Federal de 487 São Paulo, Sao Paulo), Prof. Helena Hachul (Departamento de Psicobiologia, Universidade 488 Federal de São Paulo, Sao Paulo; Departamento de Ginecologia, Universidade Federal de São 489 Paulo, Sao Paulo), Dr. Iuliana Hartescu (Clinical Sleep Research Unit, Loughborough 490 University, Loughborough), Dr. Arun Kumar (Department of Physiology, Seth G. S. Medical

491 Collage \& K. E. M. Hospital, Mumbai), Dr. Kathryn J. Reid (Department of Neurology and 492 Center for Circadian and Sleep Medicine, Northwestern University Feinberg School of 493 Medicine, Chicago, IL), Prof. Phyllis C. Zee (Department of Neurology and Center for Circadian 494 and Sleep Medicine, Northwestern University Feinberg School of Medicine, Chicago, IL) and 495 Assistant Professor Dr. Aileen WK Chan (The Nethersole School of Nursing, The Chinese 496 University of Hong Kong, Hong Kong), the authors of the included study, for providing the 
497 detailed information. We thank Dr. Jessie Chan and Prof. Cecilia Chan from Department of 498 Social Work and Social Administration, Centre on Behavioral Health, The University of Hong 499 Kong, Hong Kong, for kindly providing valuable unpublished data. We are grateful to Dr.

500 Kiyomi Shinohara (Department of Health Promotion and Human Behavior, Kyoto University 501 Graduate School of Medicine/ School of Public Health, Kyoto) for helping to make scope of the 502 review and providing information for PsycNet to enable screening in PsycINFO. We are grateful 503 to Dr. Kazuhiro Uda (Office for Infectious Control, National Center for Child Health and

504 Development, Tokyo) for helping collect references. We would like to thank Editage 505 (www.editage.jp) for English language editing. 


\section{REFERENCES}

508 Afonso RF, Hachul H, Kozasa EH, Oliveira Dde S, Goto V, Rodrigues D, Tufik S, Leite JR. 2012. Yoga decreases insomnia in postmenopausal women: a randomized clinical trial. Menopause 19:186-193. 10.1097/gme.0b013e318228225f

511 Allain H, Bentue-Ferrer D, Polard E, Akwa Y, Patat A. 2005. Postural instability and consequent falls and hip fractures associated with use of hypnotics in the elderly: a comparative review. Drugs \& Aging 22:749-765.

\section{4}

515

516

517

518

519

520

521

522

523

524 525

Andersen K, Farahmand B, Ahlbom A, Held C, Ljunghall S, Michaelsson K, Sundstrom J. 2013. Risk of arrhythmias in 52755 long-distance cross-country skiers: a cohort study. European Heart Journal 34:3624-3631. 10.1093/eurheartj/eht188

Backhaus J, Junghanns K, Broocks A, Riemann D, Hohagen F. 2002. Test-retest reliability and validity of the Pittsburgh Sleep Quality Index in primary insomnia. Journal of Psychosomatic Research 53:737-740.

Baglioni C, Battagliese G, Feige B, Spiegelhalder K, Nissen C, Voderholzer U, Lombardo C, Riemann D. 2011. Insomnia as a predictor of depression: a meta-analytic evaluation of longitudinal epidemiological studies. Journal of Affective Disorders 135:10-19. 10.1016/j.jad.2011.01.011

Bastien CH, Vallieres A, Morin CM. 2001. Validation of the Insomnia Severity Index as an outcome measure for insomnia research. Sleep Medicine 2:297-307.

Bauer M, Bschor T, Pfennig A, Whybrow PC, Angst J, Versiani M, Moller HJ, Disorders WTFoUD. 2007. World Federation of Societies of Biological Psychiatry (WFSBP) guidelines for biological treatment of unipolar depressive disorders in primary care. World Journal of Biological Psychiatry 8:67-104. 10.1080/15622970701227829 
530 Bauer M, Pfennig A, Severus E, Whybrow PC, Angst J, Moller HJ, World Federation of

531 Societies of Biological Psychiatry. Task Force on Unipolar Depressive D. 2013. World

532 Federation of Societies of Biological Psychiatry (WFSBP) guidelines for biological treatment of unipolar depressive disorders, part 1: update 2013 on the acute and

Bauer M, Severus E, Kohler S, Whybrow PC, Angst J, Moller HJ, Wfsbp Task Force on Treatment Guidelines for Unipolar Depressive D. 2015. World Federation of Societies of Biological Psychiatry (WFSBP) guidelines for biological treatment of unipolar continuation treatment of unipolar depressive disorders. World Journal of Biological Psychiatry 14:334-385. 10.3109/15622975.2013.804195

Bauer

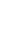

(1)

$$
\text { depressive disorders. part 2: maintenance treatment of major depressive disorder-update }
$$
2015. World Journal of Biological Psychiatry 16:76-95.

$10.3109 / 15622975.2014 .1001786$

Bjorngaard JH, Bjerkeset O, Romundstad P, Gunnell D. 2011. Sleeping problems and suicide in 75,000 Norwegian adults: a 20 year follow-up of the HUNT I study. Sleep 34:1155-1159.

548 Chan AW, Yu DS, Choi KC, Lee DT, Sit JW, Chan HY. 2016. Tai chi qigong as a means to improve night-time sleep quality among older adults with cognitive impairment: a pilot randomized controlled trial. Clinical Interventions in Aging 11:1277-1286. 10.2147/CIA.S111927 
552 Chan J, Li A, Chan C, So K, Chen J, Ji X, Yuen L, Chung K, Ng S. 2017. Qigong exercise

553

554

555

556

557

558

559

560

561

562

563

564

565

566

567

568

569

570

571

572

573

574

improved quality of sleep and reduced interleukin- 1 beta and interleukin- 6 among

persons with depressive symptoms and sleep disturbances: a randomized controlled trial.

Sleep 40:A405. 10.1093/sleepj/zsx050.1086

Chen LJ, Fox KR, Ku PW, Chang YW. 2016. Effects of aquatic exercise on sleep in older adults with mild sleep impairment: a randomized controlled trial. International Journal of Behavioral Medicine 23:501-506. 10.1007/s12529-015-9492-0

Chennaoui M, Arnal PJ, Sauvet F, Leger D. 2015. Sleep and exercise: a reciprocal issue? Sleep Medicine Reviews 20:59-72. 10.1016/j.smrv.2014.06.008

Chiu HY, Chang LY, Hsieh YJ, Tsai PS. 2016. A meta-analysis of diagnostic accuracy of three screening tools for insomnia. Journal of Psychosomatic Research 87:85-92.

10.1016/j.jpsychores.2016.06.010

De Mello MT, Fernandez AC, Tufik S. 2000. Levantamento Epidemiológico da prática de atividade física na cidade de São Paulo. Revista Brasileira de Medicina do Esporte 6:119-124.

DerSimonian R, Laird N. 1986. Meta-analysis in clinical trials. Controlled Clinical Trials 7:177188.

Driver HS, Taylor SR. 2000. Exercise and sleep. Sleep Medicine Reviews 4:387-402. 10.1053/smrv.2000.0110

Edinger JD, Bonnet MH, Bootzin RR, Doghramji K, Dorsey CM, Espie CA, Jamieson AO, McCall WV, Morin CM, Stepanski EJ, American Academy of Sleep Medicine Work G. 2004. Derivation of research diagnostic criteria for insomnia: report of an American Academy of Sleep Medicine Work Group. Sleep 27:1567-1596. 
575 Fernandez-Mendoza J, Vgontzas AN, Liao D, Shaffer ML, Vela-Bueno A, Basta M, Bixler EO.

576 2012. Insomnia with objective short sleep duration and incident hypertension: the Penn

577 State Cohort. Hypertension 60:929-935. 10.1161/HYPERTENSIONAHA.112.193268

578 Gebhart C, Erlacher D, Schredl M. 2011. Moderate exercise plus sleep education improves selfreported sleep quality, daytime mood, and vitality in adults with chronic sleep

580

581 complaints: a waiting list-controlled trial. Sleep Disorders 2011:809312.

582 Gilbert SS, van den Heuvel CJ, Ferguson SA, Dawson D. 2004. Thermoregulation as a sleep 583 signalling system. Sleep Medicine Reviews 8:81-93. 10.1016/S1087-0792(03)00023-6

584 Guilleminault C, Clerk A, Black J, Labanowski M, Pelayo R, Claman D. 1995. Nondrug 585 586 treatment trials in psychophysiologic insomnia. Archives of Internal Medicine 155:838-

Guyatt G, Oxman AD, Akl EA, Kunz R, Vist G, Brozek J, Norris S, Falck-Ytter Y, Glasziou P, 588 DeBeer H, Jaeschke R, Rind D, Meerpohl J, Dahm P, Schunemann HJ. 2011. GRADE guidelines: 1. Introduction-GRADE evidence profiles and summary of findings tables. Journal of Clinical Epidemiology 64:383-394. 10.1016/j.jclinepi.2010.04.026

Hartescu I, Morgan K, Stevinson CD. 2015. Increased physical activity improves sleep and mood outcomes in inactive people with insomnia: a randomized controlled trial. Journal of Sleep Research 24:526-534. 10.1111/jsr.12297

Higgins J, Green S. 2011. Cochrane Handbook for Systematic Reviews of Interventions Version 596 5.1.0 [updated March 2011]. Available at http://handbook-5-1.cochrane.org/ (accessed 2 June 2018). 
597 Hughes CM, McCullough CA, Bradbury I, Boyde C, Hume D, Yuan J, Quinn F, McDonough

598

599

600

601

602

603

604

605

606

607

608

609

610

611

612

613

614

615

616

617

618

SM. 2009. Acupuncture and reflexology for insomnia: a feasibility study. Acupuncture in Medicine 27:163-168. 10.1136/aim.2009.000760

Irwin MR, Olmstead R, Carrillo C, Sadeghi N, Breen EC, Witarama T, Yokomizo M, Lavretsky H, Carroll JE, Motivala SJ, Bootzin R, Nicassio P. 2014. Cognitive behavioral therapy vs. Tai Chi for late life insomnia and inflammatory risk: a randomized controlled comparative efficacy trial. Sleep 37:1543-1552. 10.5665/sleep.4008

Kern W, Perras B, Wodick R, Fehm HL, Born J. 1995. Hormonal secretion during nighttime sleep indicating stress of daytime exercise. Journal of Applied Physiology 79:1461-1468. 10.1152/jappl.1995.79.5.1461

Kim K, Uchiyama M, Okawa M, Liu X, Ogihara R. 2000. An epidemiological study of insomnia among the Japanese general population. Sleep 23:41-47.

Kredlow MA, Capozzoli MC, Hearon BA, Calkins AW, Otto MW. 2015. The effects of physical activity on sleep: a meta-analytic review. Journal of Behavioral Medicine 38:427-449. $10.1007 / \mathrm{s} 10865-015-9617-6$

Kripke DF. 2016. Mortality Risk of Hypnotics: Strengths and Limits of Evidence. Drug Safety 39:93-107. 10.1007/s40264-015-0362-0

Kubitz KA, Landers DM, Petruzzello SJ, Han M. 1996. The effects of acute and chronic exercise on sleep. A meta-analytic review. Sports Medicine 21:277-291.

Lack LC, Gradisar M, Van Someren EJ, Wright HR, Lushington K. 2008. The relationship between insomnia and body temperatures. Sleep Medicine Reviews 12:307-317. 10.1016/j.smrv.2008.02.003 
619 Laugsand LE, Vatten LJ, Platou C, Janszky I. 2011. Insomnia and the risk of acute myocardial

620 infarction: a population study. Circulation 124:2073-2081.

621 10.1161/CIRCULATIONAHA.111.025858

622 Liberati A, Altman DG, Tetzlaff J, Mulrow C, Gotzsche PC, Ioannidis JP, Clarke M, Devereaux PJ, Kleijnen J, Moher D. 2009. The PRISMA statement for reporting systematic reviews and meta-analyses of studies that evaluate health care interventions: explanation and elaboration. PLOS Medicine 6:e1000100. 10.1371/journal.pmed.1000100

Lichstein KL, Durrence HH, Taylor DJ, Bush AJ, Riedel BW. 2003. Quantitative criteria for insomnia. Behaviour Research and Therapy 41:427-445.

Mercier J, Savard J, Bernard P. 2017. Exercise interventions to improve sleep in cancer patients: A systematic review and meta-analysis. Sleep Medicine Reviews 36:43-56.

630 10.1016/j.smrv.2016.11.001 Cochrane Database of Systematic Reviews:CD003404. 10.1002/14651858.CD003404

Montgomery P, Dennis J. 2004. A systematic review of non-pharmacological therapies for sleep problems in later life. Sleep Medicine Reviews 8:47-62. 10.1016/S1087-0792(03)00026-1

Morgan K. 2003. Daytime activity and risk factors for late-life insomnia. Journal of Sleep Research 12:231-238. Lee-Chiong T, Owens J, Pancer J, Swick T, American Academy of Sleep Medicine. 2006. Practice parameters for the psychological and behavioral treatment of insomnia: an update. An American Academy of Sleep Medicine report. Sleep 29:1415-1419. 
641 Morin CM, Belleville G, Belanger L, Ivers H. 2011. The Insomnia Severity Index: psychometric

642 indicators to detect insomnia cases and evaluate treatment response. Sleep 34:601-608.

643 Morin CM, Bootzin RR, Buysse DJ, Edinger JD, Espie CA, Lichstein KL. 2006. Psychological

644 and behavioral treatment of insomnia:update of the recent evidence (1998-2004). Sleep

$645 \quad 29: 1398-1414$.

646 Morita Y, Sasai-Sakuma T, Inoue Y. 2017. Effects of acute morning and evening exercise on

647 subjective and objective sleep quality in older individuals with insomnia. Sleep Medicine

$648 \quad 34: 200-208.10 .1016 /$ j.sleep.2017.03.014

649 Murphy PJ, Campbell SS. 1997. Nighttime drop in body temperature: a physiological trigger for $650 \quad$ sleep onset? Sleep 20:505-511.

651 Nakazaki C, Noda A, Koike Y, Yamada S, Murohara T, Ozaki N. 2012. Association of insomnia 652

653 and short sleep duration with atherosclerosis risk in the elderly. American Journal of

654 Hypertension 25:1149-1155. 10.1038/ajh.2012.107

National Institutes of Health. 2005. National Institutes of Health State of the Science Conference statement on Manifestations and Management of Chronic Insomnia in Adults, June 13-

NICE. 2012. Physical activity: walking and cycling. Available at https://www.nice.org.uk/guidance/ph41 (accessed 2 June 2018).

NICE. 2013. Physical activity: brief advice for adults in primary care. Available at https://www.nice.org.uk/guidance/ph44 (accessed 2 June 2018).

661 NICE. 2015. Physical activity: for NHS staff, patients and carers. Available at https://www.nice.org.uk/guidancelqs84 (accessed 2 June 2018). 
663 Passos GS, Poyares D, Santana MG, D'Aurea CV, Youngstedt SD, Tufik S, de Mello MT. 2011.

664 Effects of moderate aerobic exercise training on chronic primary insomnia. Sleep

$665 \quad$ Medicine 12:1018-1027. 10.1016/j.sleep.2011.02.007

666 Passos GS, Poyares D, Santana MG, Garbuio SA, Tufik S, Mello MT. 2010. Effect of acute

667 physical exercise on patients with chronic primary insomnia. Journal of Clinical Sleep

$668 \quad$ Medicine 6:270-275.

669 Passos GS, Poyares DL, Santana MG, Tufik S, Mello MT. 2012. Is exercise an alternative

670 treatment for chronic insomnia? Clinics 67:653-660.

671 Pigeon WR, Pinquart M, Conner K. 2012. Meta-analysis of sleep disturbance and suicidal

672 thoughts and behaviors. Journal of Clinical Psychiatry 73:e1160-1167.

$673 \quad 10.4088 / \mathrm{JCP} .11 \mathrm{r} 07586$

674 Qaseem A, Kansagara D, Forciea MA, Cooke M, Denberg TD. 2016. Management of chronic

675 insomnia disorder in adults: A clinical practice guideline from the American College of

676 Physicians. Annals of Internal Medicine 165:125-133. 10.7326/M15-2175

677 Reid KJ, Baron KG, Lu B, Naylor E, Wolfe L, Zee PC. 2010. Aerobic exercise improves self678 reported sleep and quality of life in older adults with insomnia. Sleep Medicine 11:934-

$679940.10 .1016 /$ j.sleep.2010.04.014

680 Riemann D, Nissen C, Palagini L, Otte A, Perlis ML, Spiegelhalder K. 2015. The neurobiology, 681 investigation, and treatment of chronic insomnia. Lancet Neurology 14:547-558.

682 10.1016/S1474-4422(15)00021-6

683 Scheen AJ, Byrne MM, Plat L, Leproult R, Van Cauter E. 1996. Relationships between sleep 684 quality and glucose regulation in normal humans. American Journal of Physiology 685 271:E261-270. 10.1152/ajpendo.1996.271.2.E261 
686 Schutte-Rodin S, Broch L, Buysse D, Dorsey C, Sateia M. 2008. Clinical guideline for the 687 evaluation and management of chronic insomnia in adults. Journal of Clinical Sleep $688 \quad$ Medicine 4:487-504.

689 Tadayon M, Abedi P, Farshadbakht F. 2016. Impact of pedometer-based walking on menopausal 690 women's sleep quality: a randomized controlled trial. Climacteric 19:364-368.

691 $10.3109 / 13697137.2015 .1123240$

692 Taheri M, Arabameri E. 2012. The effect of sleep deprivation on choice reaction time and 693 anaerobic power of college student athletes. Asian Journal of Sports Medicine 3:15-20.

694

695

696 697 698 699 700 701 702
Taheri M, Irandoust K. 2018. The Exercise-Induced Weight Loss Improves Self-Reported Quality of Sleep in Obese Elderly Women with Sleep Disorders. Sleep and Hypnosis : A Journal of Clinical Neurosciences and Psychopathology 20:54-59.

Tan X, Alen M, Wiklund P, Partinen M, Cheng S. 2016. Effects of aerobic exercise on homebased sleep among overweight and obese men with chronic insomnia symptoms: a randomized controlled trial. Sleep Medicine 25:113-121. 10.1016/j.sleep.2016.02.010

Tang MF, Liou TH, Lin CC. 2010. Improving sleep quality for cancer patients: benefits of a home-based exercise intervention. Supportive Care in Cancer 18:1329-1339. $10.1007 / \mathrm{s} 00520-009-0757-5$

Tuckow AP, Rarick KR, Kraemer WJ, Marx JO, Hymer WC, Nindl BC. 2006. Nocturnal growth hormone secretory dynamics are altered after resistance exercise: deconvolution analysis of 12-hour immunofunctional and immunoreactive isoforms. American Journal of Physiology-Regulatory, Integrative and Comparative Physiology 291:R1749-1755. 10.1152/ajpregu.00854.2005 
708 University of Texas at Austin School of Nursing. 2014. Clinical guideline for the treatment of

709 primary insomnia in middle-aged and older adults. Available at

$710 \quad$ http://www.multiplechronicconditions.org/assets/pdf/Insomnia\%20Guidelines/AHRQ_20

711 14_Clinical guideline for the treatment of primary insomnia in middle-

712 aged_and_older_adults.pdf (accessed 2 June 2018).

713 Wilson SJ, Nutt DJ, Alford C, Argyropoulos SV, Baldwin DS, Bateson AN, Britton TC, Crowe

714 C, Dijk DJ, Espie CA, Gringras P, Hajak G, Idzikowski C, Krystal AD, Nash JR, Selsick

715 H, Sharpley AL, Wade AG. 2010. British Association for Psychopharmacology

716 consensus statement on evidence-based treatment of insomnia, parasomnias and circadian

717 rhythm disorders. Journal of Psychopharmacology 24:1577-1601.

$718 \quad 10.1177 / 0269881110379307$

719 Yang PY, Ho KH, Chen HC, Chien MY. 2012. Exercise training improves sleep quality in

720 middle-aged and older adults with sleep problems: a systematic review. Journal of

$721 \quad$ Physiotherapy 58:157-163. 10.1016/S1836-9553(12)70106-6

722 Youngstedt SD. 2005. Effects of exercise on sleep. Clinics in Sports Medicine 24:355-365, xi.

$723 \quad 10.1016 / j . c s m .2004 .12 .003$

724 Youngstedt SD, Kline CE. 2006. Epidemiology of exercise and sleep. Sleep and Biological

$725 \quad$ Rhythms $4: 215-221.10 .1111 / \mathrm{j} .1479-8425.2006 .00235 . \mathrm{x}$

726 Youngstedt SD, O'Connor PJ, Dishman RK. 1997. The effects of acute exercise on sleep: a

727 quantitative synthesis. Sleep 20:203-214.

728 
Figure 1

PRISMA 2009 flow diagram

CENTRAL: Cochrane Central Register of Controlled Trials; ICTRP, International Clinical Trials

Registry Platform; RCTs, randomized controlled trials 


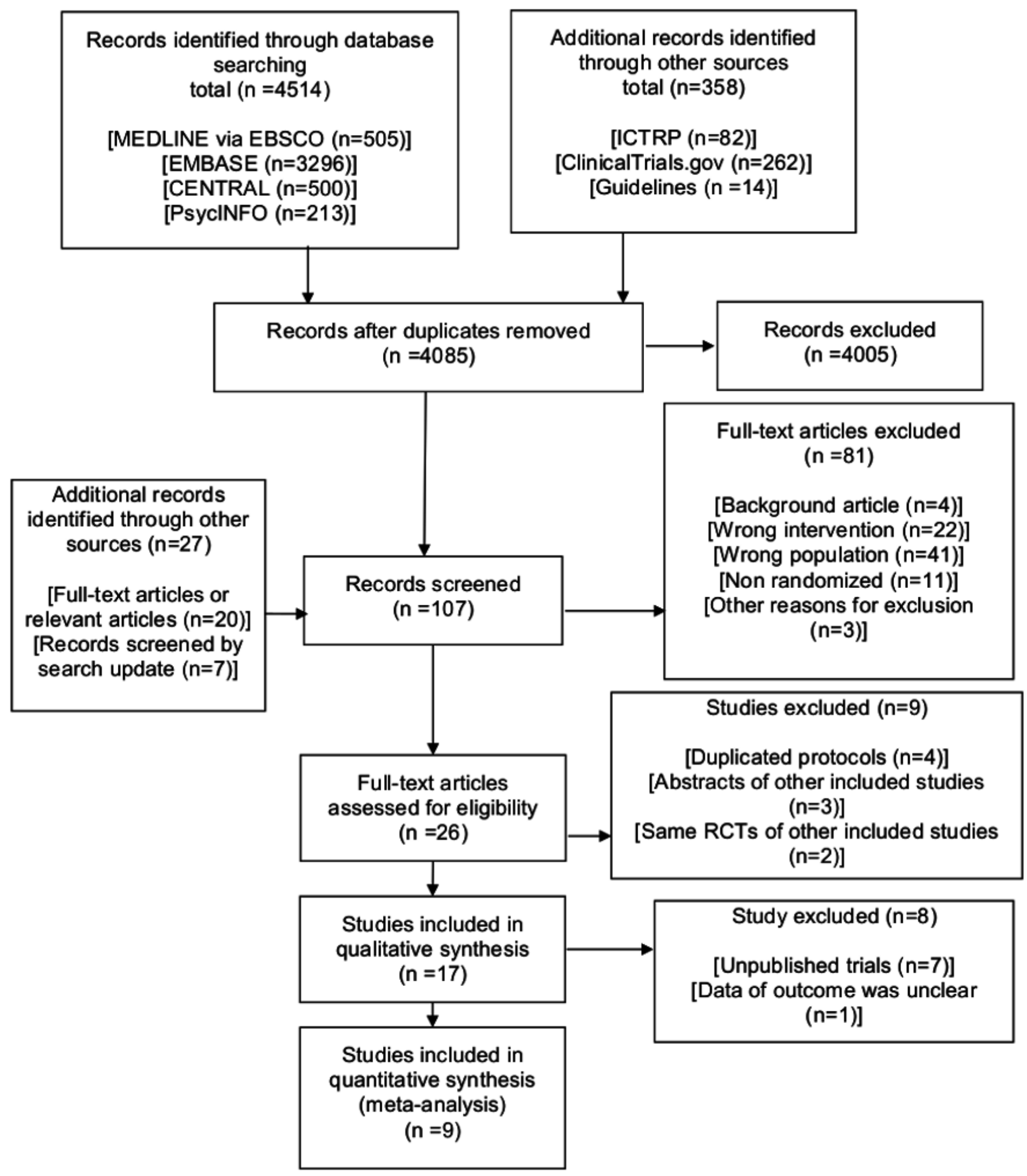


Figure 2

(A) Risk of bias graph (B) Risk of bias summary

(A) Review author judgments about the risk for each bias item presented as percentages

across all included trials. (B) Review author judgments about the risk for each bias item in all included trials. 
A

Random sequence generation (selection bias)

Allocation concealment (selection bias)

Blinding of participants and personnel (performance bias)

Blinding of outcome assessment (detection bias)

Incomplete outcome data (attrition bias)

Selective reporting (reporting bias)

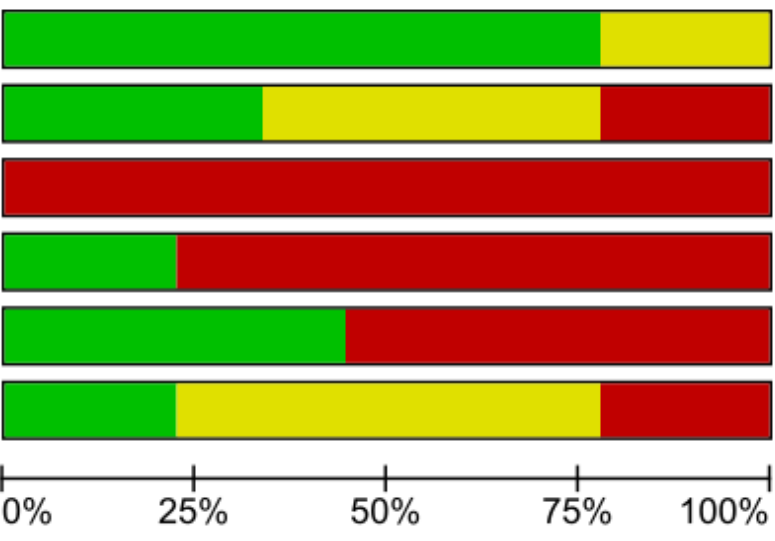

B
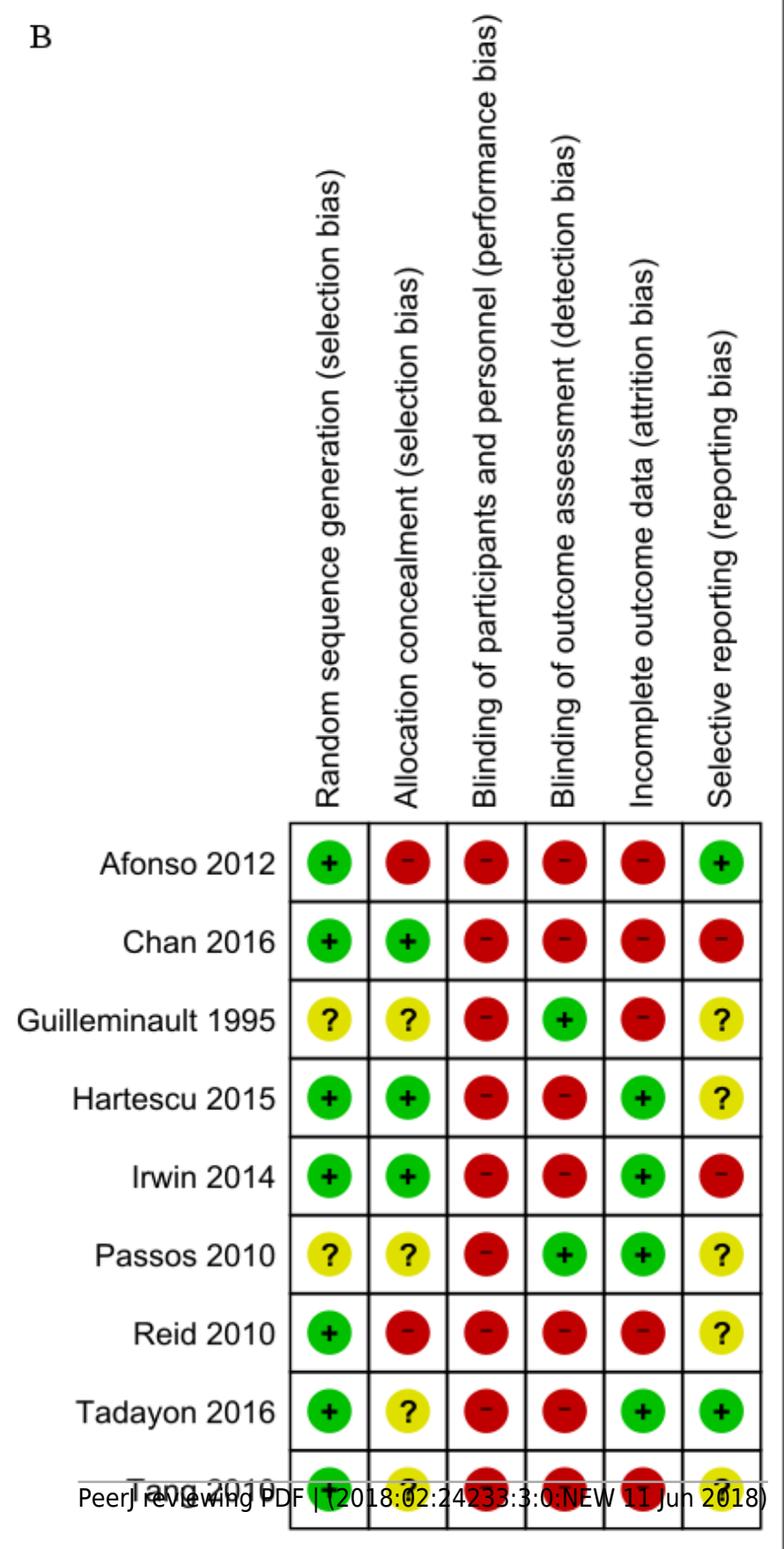


\section{Figure 3}

(A) Forest plot of comparison: Total PSQI score (B) Forest plot of comparison: Sleep efficiency (\%) (C) Forest plot of comparison: Total ISI score
(A) Total PSQI score was measured subjectively.
IV, inverse variance; PSQI, Pittsburgh Sleep Quality Index
(B) Sleep efficiency was measured objectively by the devices (e.g., PSG, actigraphy).
IV, inverse variance; PSG, polysomnograph
(C) Total ISI score was measured subjectively.
ISI, Insomnia Severity Index; IV, inverse variance 


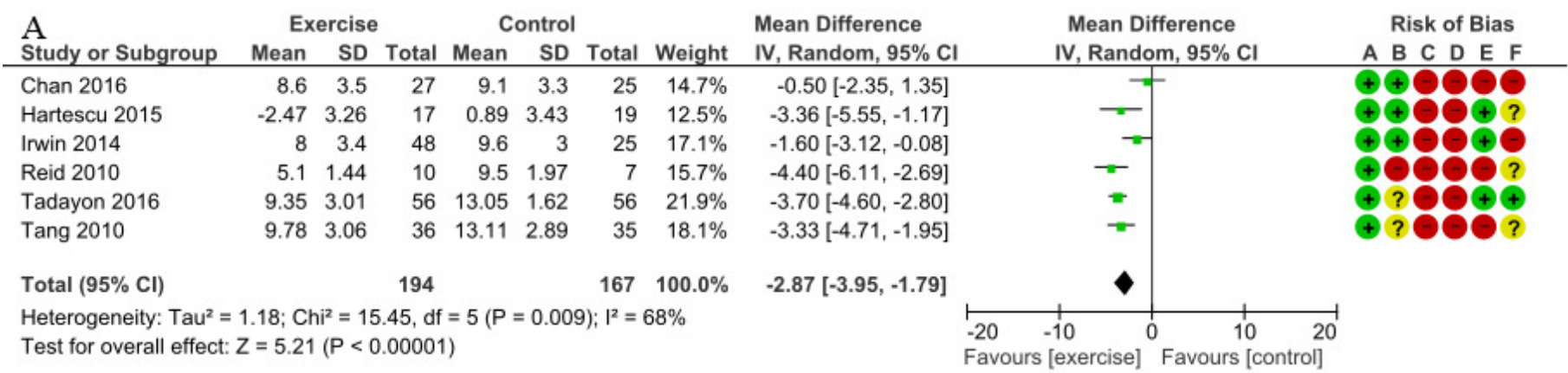

Risk of bias legend
(A) Random sequence generation (selection bias)
(B) Allocation concealment (selection bias)
(C) Blinding of participants and personnel (performance bias)
(D) Blinding of outcome assessment (detection bias)
(E) Incomplete outcome data (attrition bias)
(F) Selective reporting (reporting bias)

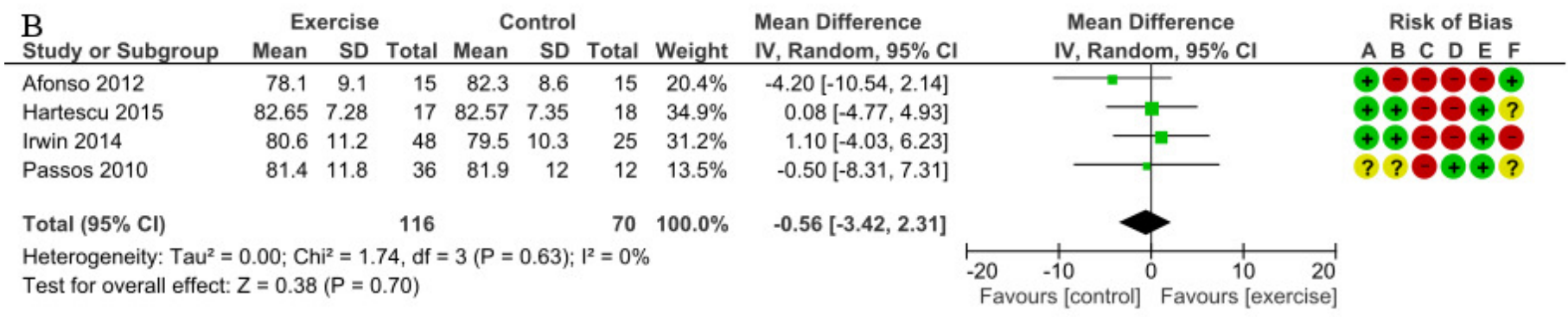

Risk of bias legend
(A) Random sequence generation (selection bias)
(B) Allocation concealment (selection bias)
(C) Blinding of participants and personnel (performance bias)
(D) Blinding of outcome assessment (detection bias)
(E) Incomplete outcome data (attrition bias)
(F) Selective reporting (reporting bias)

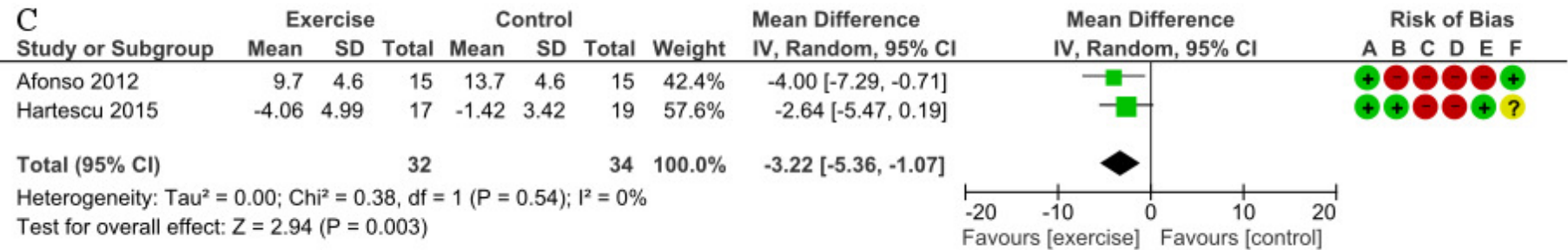

\section{Risk of bias legend}
(A) Random sequence generation (selection bias)
(B) Allocation concealment (selection bias)
(C) Blinding of participants and personnel (performance bias)
(D) Blinding of outcome assessment (detection bias)
(E) Incomplete outcome data (attrition bias)
(F) Selective reporting (reporting bias) 


\section{Table $\mathbf{1}$ (on next page)}

\section{Summary of findings}

*The risk in the intervention group (and its $95 \% \mathrm{Cl}$ ) is based on the assumed risk in the comparison group and the relative effect of the intervention (and its $95 \% \mathrm{Cl}$ ).

ISI, Insomnia Severity Index; MD, mean differences; OIS, optimal information size; GRADE, Grading of Recommendations, Assessment, Development, and Evaluation; OR, odds ratio; PSQI, Pittsburgh Sleep Quality Index; RCTs, randomized controlled trials; RR, risk ratio

GRADE working group grades of evidence

High quality: We are very confident that the true effect lies close to that of the estimate of the effect

Moderate quality: We are moderately confident in the effect estimate: The true effect is likely to be close to the estimate of the effect, but a substantial difference is possible

Low quality: Our confidence in the effect estimate is limited: The true effect may be substantially different from the estimate of the effect

Very low quality: We have very little confidence in the effect estimate: The true effect is likely to be substantially different from the estimate of effect

${ }^{1}$ Participants were not blinded. ${ }^{2}$ The outcome assessors were not blinded. ${ }^{3}$ Sample size was small. Sample size did not meet criteria of optimal information size (OIS) (400). OIS was 400 if alpha $=0.05$, beta $=0.2$, delta $=0.2 .{ }^{4}$ Allocation concealment was not done in $40 \%$ of participants. ${ }^{5}$ There were incomplete outcome data in $40 \%$ of participants. ${ }^{6}$ There were incomplete outcome data in $25 \%$ of participants. ${ }^{7}$ There were incomplete outcome data in $50 \%$ of participants. ${ }^{8}$ Allocation concealment was not done in $30 \%$ of participants. 
1 Table 1. Summary of findings

\begin{tabular}{|c|c|c|c|c|c|}
\hline $\begin{array}{c}\text { Outcomes } \\
\text { (time frame) }\end{array}$ & $\begin{array}{c}\text { Number of } \\
\text { participants } \\
\text { (studies) in follow- } \\
\text { up }\end{array}$ & $\begin{array}{l}\text { Quality of } \\
\text { evidence } \\
\text { (GRADE) }\end{array}$ & $\begin{array}{l}\text { Relative effect } \\
\qquad(95 \% \text { CI })\end{array}$ & $\begin{array}{c}\text { Anticipated } \\
\text { absolute effects }{ }^{*} \\
(95 \% \text { CI })\end{array}$ & \\
\hline & & & & Risk with control & $\begin{array}{l}\text { Risk difference } \\
\text { with exercise }\end{array}$ \\
\hline $\begin{array}{l}\text { Total PSQI score } \\
\text { (8 wks to } 6 \mathrm{mos})\end{array}$ & 361 & $\oplus \oplus \ominus \ominus$ & - & & $\begin{array}{l}\text { MD } 2.87 \text { point } \\
\text { lower }\end{array}$ \\
\hline Scale: 0 to 21 & (6 RCTs) & LOW $^{123}$ & & & $\begin{array}{c}\text { (3.95 lower to } 1.79 \\
\text { lower) }\end{array}$ \\
\hline $\begin{array}{c}\text { Sleep efficiency }(\%) \\
(1 \mathrm{~d} \text { to } 6 \text { mos })\end{array}$ & 186 & $\oplus \oplus \oplus \ominus$ & - & & MD $0.56 \%$ lower \\
\hline $\begin{array}{c}\text { assessed with: } \\
\text { polysomnography } \\
\text { and actigraphy }\end{array}$ & (4 RCTs) & MODERATE $^{3}$ & & & $\begin{array}{c}\text { (3.42 lower to } 2.31 \\
\text { higher) }\end{array}$ \\
\hline \multicolumn{6}{|l|}{ Scale: 0 to 100} \\
\hline $\begin{array}{c}\text { Total ISI score } \\
(4-6 \mathrm{mos})\end{array}$ & 66 & $\oplus \ominus \ominus \ominus$ & - & & $\begin{array}{c}\text { MD } 3.22 \text { point } \\
\text { lower }\end{array}$ \\
\hline Scale: 0 to 28 & (2 RCTs) & VERY LOW 12345 & & & $\begin{array}{c}\text { (5.36 lower to } 1.07 \\
\text { lower) }\end{array}$ \\
\hline $\begin{array}{l}\text { Sleep onset latency } \\
\text { (minute) }\end{array}$ & 206 & $\oplus \oplus \ominus \ominus$ & - & & $\begin{array}{l}\text { MD } 1.9 \text { minutes } \\
\text { higher }\end{array}$ \\
\hline
\end{tabular}




\begin{tabular}{|c|c|c|c|c|}
\hline ( $1 \mathrm{~d}$ to $6 \mathrm{mos})$ & & & & \\
\hline & (5 RCTs) & LOW $^{36}$ & & $\begin{array}{c}\text { (3.63 lower to } 7.43 \\
\text { higher) }\end{array}$ \\
\hline \multirow{2}{*}{$\begin{array}{c}\text { Total sleep time } \\
\text { (minute) } \\
\text { (1 d to } 6 \mathrm{mos})\end{array}$} & 206 & $\oplus \oplus \Theta \Theta$ & - & $\begin{array}{c}\text { MD } 4.32 \text { minutes } \\
\text { higher }\end{array}$ \\
\hline & (5 RCTs) & LOW $^{36}$ & & $\begin{array}{l}\text { (9.19 lower to } \\
17.84 \text { higher) }\end{array}$ \\
\hline \multirow[t]{2}{*}{$\begin{array}{l}\text { All adverse events } \\
\qquad(2-6 \mathrm{mos})\end{array}$} & 150 & $\oplus \ominus \ominus \ominus$ & - & \\
\hline & (4 RCTs) & VERY LOW 12378 & & \\
\hline
\end{tabular}

3 *The risk in the intervention group (and its 95\% CI) is based on the assumed risk in the comparison group and the relative effect of the

4 intervention (and its $95 \% \mathrm{CI}$ ).

5 ISI, Insomnia Severity Index; MD, mean differences; OIS, optimal information size; GRADE, Grading of Recommendations,

6 Assessment, Development, and Evaluation; OR, odds ratio; PSQI, Pittsburgh Sleep Quality Index; RCTs, randomized controlled trials;

$7 \quad \mathrm{RR}$, risk ratio 
9 GRADE working group grades of evidence

10 High quality: We are very confident that the true effect lies close to that of the estimate of the effect

11 Moderate quality: We are moderately confident in the effect estimate: The true effect is likely to be close to the estimate of the effect,

12 but a substantial difference is possible

13 Low quality: Our confidence in the effect estimate is limited: The true effect may be substantially different from the estimate of the

14 effect

15 Very low quality: We have very little confidence in the effect estimate: The true effect is likely to be substantially different from the

16 estimate of effect

$17{ }^{1}$ Participants were not blinded.

$18{ }^{2}$ The outcome assessors were not blinded.

$19{ }^{3}$ Sample size was small. Sample size did not meet criteria of optimal information size (OIS) (400). OIS was 400 if alpha $=0.05$, beta $=$

200.2 , delta $=0.2$ 
$21{ }^{4}$ Allocation concealment was not done in $40 \%$ of participants.

$22{ }^{5}$ There were incomplete outcome data in $40 \%$ of participants.

$23{ }^{6}$ There were incomplete outcome data in $25 \%$ of participants.

$24{ }^{7}$ There were incomplete outcome data in $50 \%$ of participants.

$25{ }^{8}$ Allocation concealment was not done in $30 \%$ of participants. 


\section{Table 2 (on next page)}

Summary of the published studies including qualitative synthesis

Chan et al. 2017 included a qualitative synthesis but excluded a quantitative synthesis because the trial did not include outcomes data for a meta-analysis.

DSM, Diagnostic and Statistical Manual of Mental Disorders; ICSD, International Classification of Sleep

Disorders; PSQI, Pittsburgh Sleep Quality Index; RDC, research diagnostic criteria 
1 Table 2. Summary of the published studies including qualitative synthesis

\begin{tabular}{|c|c|c|c|c|c|c|c|}
\hline Source & Setting & Patients, N & Age & Inclusion criteria & Exercise type & $\begin{array}{l}\text { Exercise } \\
\text { frequency }\end{array}$ & $\begin{array}{l}\text { Exercise } \\
\text { duration }\end{array}$ \\
\hline $\begin{array}{l}\text { Afonso et al. } \\
2012\end{array}$ & Elsewhere & 61 & 50 to 65 years & $\begin{array}{l}\text { Postmenopausal } \\
\text { women with } \\
\text { primary insomnia } \\
\text { meeting DSM-4 }\end{array}$ & $\begin{array}{c}\text { Aerobic } \\
\text { (other aerobic) }\end{array}$ & 2 session/wk & $4 \operatorname{mos}$ \\
\hline $\begin{array}{c}\text { Chan et al. } \\
2016\end{array}$ & Elsewhere & 52 & $\begin{array}{c}60 \text { years or } \\
\text { older }\end{array}$ & $\begin{array}{l}\text { Older adults with } \\
\text { cognitive } \\
\text { impairment with } \\
\text { CPSQI > 5 }\end{array}$ & $\begin{array}{c}\text { Aerobic } \\
\text { (other aerobic) }\end{array}$ & 2 session/wk & $2 \operatorname{mos}$ \\
\hline $\begin{array}{c}\text { Chan et al. } \\
2017\end{array}$ & Elsewhere & Unknown & $\begin{array}{c}18 \text { years or } \\
\text { older }\end{array}$ & $\begin{array}{l}\text { Participants with } \\
\text { mild to moderate } \\
\text { depression and } \\
\text { PSQI > 5 }\end{array}$ & $\begin{array}{c}\text { Aerobic } \\
\text { (other aerobic) }\end{array}$ & 3 session/wk & 8 wks \\
\hline $\begin{array}{l}\text { Guilleminault } \\
\text { et al. } 1995\end{array}$ & At home & 32 & 34 to 55 years & $\begin{array}{c}\text { Patients with } \\
\text { psychophysiologic } \\
\text { insomnia meeting } \\
\text { predetermined } \\
\text { criteria }\end{array}$ & $\begin{array}{l}\text { Aerobic } \\
\text { (walking) }\end{array}$ & $7 \mathrm{~d} / \mathrm{wk}$ & 4 wks \\
\hline $\begin{array}{l}\text { Hartescu et al. } \\
\qquad 2015\end{array}$ & At home & 41 & $\begin{array}{l}40 \text { years or } \\
\text { older }\end{array}$ & $\begin{array}{l}\text { Inactive adults } \\
\text { meeting RDC for } \\
\text { insomnia }\end{array}$ & $\begin{array}{l}\text { Aerobic } \\
\text { (walking) }\end{array}$ & $5 \mathrm{~d} / \mathrm{wk}$ & $6 \operatorname{mos}$ \\
\hline Irwin et al. & Elsewhere & 123 & 34 to 55 years & Older adults with & Aerobic & $1 \mathrm{~d} / \mathrm{wk}$ & $4 \operatorname{mos}$ \\
\hline
\end{tabular}




\begin{tabular}{|c|c|c|c|c|c|c|c|}
\hline 2014 & & & & $\begin{array}{l}\text { chronic and } \\
\text { primary insomnia } \\
\text { meeting DSM-IV- } \\
\text { TR and ICSD-2 }\end{array}$ & (other aerobic) & & \\
\hline $\begin{array}{c}\text { Passos et al. } \\
2010\end{array}$ & $\begin{array}{l}\text { Exercise } \\
\text { laboratory }\end{array}$ & 48 & 30 to 55 years & $\begin{array}{l}\text { Primary insomnia } \\
\text { meeting DSM-IV- } \\
\text { TR and ICSD-2 }\end{array}$ & $\begin{array}{c}\text { Aerobic } \\
\text { (walking, other } \\
\text { aerobic) }\end{array}$ & Acute & One time \\
\hline $\begin{array}{c}\text { Reid et al. } \\
2010\end{array}$ & Elsewhere & 17 & $\begin{array}{c}55 \text { years or } \\
\text { older }\end{array}$ & $\begin{array}{l}\text { Older adults with } \\
\text { insomnia meeting } \\
\text { predetermined } \\
\text { criteria }\end{array}$ & $\begin{array}{c}\text { Aerobic } \\
\text { (walking, other } \\
\text { aerobic) }\end{array}$ & 4 times per wk & $16 \mathrm{wks}$ \\
\hline $\begin{array}{l}\text { Tadayon et al. } \\
2016\end{array}$ & At home & 112 & $\begin{array}{c}\text { Mean } 52.39 \\
(\mathrm{SD} 1.65) \\
\text { years }\end{array}$ & $\begin{array}{c}\text { Postmenopausal } \\
\text { women with PSQI } \\
>5\end{array}$ & $\begin{array}{l}\text { Aerobic } \\
\text { (walking) }\end{array}$ & $7 \mathrm{~d} / \mathrm{wk}$ & $12 \mathrm{wks}$ \\
\hline $\begin{array}{c}\text { Tang et al. } \\
2010\end{array}$ & At home & 71 & $\begin{array}{c}\text { Mean } 51.80 \\
\text { (SD 12.13) } \\
\text { years }\end{array}$ & $\begin{array}{l}\text { Cancer patients } \\
\text { with PSQI > } 5\end{array}$ & $\begin{array}{l}\text { Aerobic } \\
\text { (walking) }\end{array}$ & $3 \mathrm{~d} / \mathrm{wk}$ & 8 wks \\
\hline
\end{tabular}

2

3 Chan et al. 2017 included a qualitative synthesis but excluded a quantitative synthesis because the trial did not include outcomes data 4 for a meta-analysis.

5 DSM, Diagnostic and Statistical Manual of Mental Disorders; ICSD, International Classification of Sleep Disorders; PSQI, Pittsburgh

6 Sleep Quality Index; RDC, research diagnostic criteria 